\title{
Ressenya
}

\section{Lacueva Lorenz, Maria (ed.) (2017). Didàctica Universitària dels estudis culturals Pràctiques i tendències en la Catalanísti- ca i la Hispanística/Kulturwissenschatfliche Hochschuldidaktik Praxis und Tendenzen aus Katalanistik und Hispanistik. Universitätsverlag Universaar}

\author{
José Manuel Gomis Pastor \\ Université Gustave Eiffel \\ josemanuelgomispastor@gmail.com
}

Rebut: 19 de juny del 2020

Acceptat: 30 de juny del 2020

\begin{abstract}
A la declaració Higher Education in the Twenty-first Century. Vision and Action de la UNESCO (1998: 21) es manifesten dues necessitats relacionades amb aquesta obra. La primera és educar per a la ciutadania i una participació activa en la societat i, la segona, ajudar a entendre, interpretar, preservar, ressaltar i difondre les cultures nacionals i regionals, internacionals i històriques ${ }^{1}$. En aquest volum llegirem experiències pràctiques, anàlisis de manuals $i$ estudis teòrics d'ensenyament de cultura catalana i hispànica a la universitat en contrast amb l'alemanya, que contextualitza la major part dels articles. Aquesta obra vol donar una resposta a la "indefinició" de l'ensenyament de cultura o societat perquè "d'alguna manera no s'havia dotat d'una especificitat acadèmicament nítida" i sovint s'havien considerat com un pont facilitador per als estudiants entre la llengua i la literatura. Noves veus en l'àmbit de la germanística com ara Lüsebrink i Vaillant (2013), Häg i Schweiger (2015) o Altmayer (2004, 2007, 2013), ja destacaven la necessitat de fer del Landeskunde (cultura i societat) un objecte d'investigació científica, una entitat d'estudi i recerca.
\end{abstract}

$\mathrm{Al}$ costat de la utilitat que pot tenir per als estudiants que faran estades o s'instal-laran en altres territoris, es pretén que l'assignatura de cultura es regisca sobre els principis ètics que caldria promoure: criteris de la selecció de continguts i materials, estratègies de recerca i interpretació dels estudiants o la interculturalitat crítica. Dins de la casella "cultura" vorem que es tracta de fer un acostament holístic al grup humà que la conforma, perquè parlem d'una assignatura que aglutina molts aspectes i disciplines: economia, història, ciències polítiques, llengua, literatura, art, sociologia, etc.

Entre els articles que estudien la casella "cultura" o la presència indispensable a les classes de llengua o de traducció, Antonio Lérida, a "Docencia de Cultura y Sociedad en el aula de Traducción: estrategias para el análisis del culturema”, fa palés el paper cabdal de la cultura en els estudis de traducció. L'autor subratlla la importància de la formació cultural per a tenir les competències necessàries que permeten una traducció acurada i crítica, és a dir, que reflectisca el missatge originari en el seu context cultural sense perdre significat. 
Maria Lacueva a "Didàctica de la cultura a la universitat: dels estudis culturals als estudis catalans (i viceversa)" analitza la terminologia emprada per a referir-se a la llengua i la cultura "estrangeres", tenint en compte la relació amb la diversitat de perfils dels estudiants. Denomina la cultura "estrangera" com "complementària" perquè formarà part dels constructes identitaris dels estudiants. A partir de l'anàlisi de vint-i-quatre guies docents d'assignatures de cultures complementàries d'universitats de la Xarxa Vives, Lacueva descriu les tendències que hi observa i ens presenta una radiografia dels continguts que deixa vore en sis nivells de concreció de l'ensenyament dels estudis catalans com a cultura complementària a partir de tres eixos: llengua, cultura i societat.

Si parlem de la cultura complementària, cal que establim ponts interculturals, que ens posem en la pell de l'altre. Roberto Cortés a l'article "La empatía en las clases de lengua y cultura" ens parla del paper de l'empatia a l'hora d'aprendre idiomes. En qüestions culturals, que configuren el tarannà de les persones, és crucial que mirem a través de les ulleres dels estudiants que tenim davant per comprendre el seu món. L'empatia, ens explica, entesa com una reacció natural, és una fortalesa que posseïm tothom. Les habilitats comunicatives han d'anar al costat de les habilitats afectives, ja que formen part del currículum no verbal.

Quant als articles que analitzen manuals de llengua, Rosario Herrero i Pilar Cardo a "El componente cultural en los manuales de español como lengua extranjera" examinen la presència de continguts culturals en vint-i-quatre manuals espanyols i alemanys dedicats a l'espanyol com a segona llengua des de les tres darreres dècades. Atesos els lligams entre llengua i cultura, les autores estudien la presència de la cultura, tant la legitimada (objecte d'estudi universitari) com aquella relacionada amb aspectes quotidians, modes de fer i actuar compartits per una comunitat de parlants des d'un eix temporal i espacial (l'Estat Espanyol i Alemanya).

Pel que fa a les experiències dutes a terme a l'aula, a "Uso de materiales auténticos en las clases de Cultura y Sociedad: un ejemplo práctico" Vanesa Longo reflexiona al voltant de l'ús de materials autèntics als cursos monogràfics d'ELE. Com que l'aprenentatge de llengües en l'actualitat global és força estés i molts estudiants arriben a la universitat amb un bon domini lingüístic, molts opten per un coneixement especialitzat, és a dir, per cursos centrats en aspectes socioculturals i artístics concrets, com Caminando por España. Longo fa conéixer a l'alumnat les comunitats autònomes espanyoles, i li proporciona nocions socioculturals, històriques i lingüístiques amb "materials autèntics" (Ana Mochón 2005: 2) que es poden trobar de forma natural en situacions comunicatives reals ${ }^{2}$, els quals ofereixen unes potencialitats diferents al "material didactitzat" adaptat pel docent.

Des de la necessitat de promoure la descoberta individual, a "Einführung in die Kulturwissenschaft - didaktische Perspektiven für die Hispanistik" Isabel Exner eixampla les perspectives de la programació del curs tenint en compte el desenvolupament de cadascú, l'autonomia i la desimboltura en els processos de construcció d'un mateix. A partir de les tasques i els coneixements empírics dels alumnes sobre la diversitat de la cultura hispana, es confegeix un programa pluricèntric que atén els interessos de l'alumnat: identitats territorials, socials, de gènere, l'alteritat o la qüestions de democratització històrica, on entra en joc l'opinió pròpia i la mediació cultural.

La proposta "Literatura gastronòmica catalana a l'aula" de Gemma Bernadó ens parla d'un projecte de cuina. Aquest projecte és un treball transversal, una opció engrescadora i atractiva que pot vertebrar i facilitar l'acostament a disciplines com és la història, la llengua, la literatura, la geografia, la política, la cultura i la societat. Fa dialogar la cultura canònica (textos escrits i manifestacions literàries) amb el món de la gastronomia, que acostumem a classificar com a cultura fora de l'àmbit acadèmic.

A “Landeskunde und Linguistik. Praktische Überlegungen zur Vernetzung zweier Diszipli-

2 Com ara textos, imatges fixes o animades, enregistraments de veu, textos publicitaris, etc. (Andrijevic 2010: 158) 
nen in der Hochschullehre", Julia Montemayor descriu una seqüència didàctica amb tot un seguit de tasques amb continguts lingüístics i socioculturals. Montemayor fa una aproximació a la variació lingüística i a les qüestions sociolingüístiques a partir del cas de Mèxic. L'autora preten causar en els estudiants una interconnexió duradora i una retenció dels coneixements efectiva, per això selecciona materials autèntics que visen a crear un clima de treball i d'investigació. La raó de fons dels desafiaments que aquesta seqüència implica ha de ser sempre l'aplicació i creació de materials amb continguts socioculturals i lingüístics que tinguen per objectiu l'augment de la motivació del estudiants per conèixer la realitat del context mexicà.

Finalment, Anna Subarroca i Elisabet Capdevila, a "El músic com a pedagog a l'aula de cultura i llengua estrangera", ens mostren un projecte de gires de sis músics dels Països Catalans a quatre països europeus entre 2009 i 2015. Les autores plantegen les potencialitats de la música per acostar els estudiants al panorama cultural català. La diversitat d'estil dels artistes respon a l'heterogeneitat de gustos musicals dels estudiants. Es creen contextos culturals reals amb conferències dels artistes programades a les universitats. Les autores subratllen la importància de la frescor i la proximitat entre ells i els estudiants.

Comptat i debatut, se'ns ofereix una aproximació a les noves tendències i pràctiques docents universitàries dels estudis culturals en la catalanística i la hispanística. La reflexió i el qüestionament són constants, perquè parlar de cultura i ensenyar cultura és un exercici global i transversal en les societats actuals. D'aprenentatges, se'n desprenen molts així com l'evidència de donar nom i fer una revisió crítica i constructiva de la cultura que ensenyem.

Els docents, les institucions universitàries, els estudiants, les estructures socials i tota la vida que ens envolta són/som dipositaris i generadors de cultura. Des del punt de vista del context alemany es reflexiona sobre com ho fem, amb quins materials, què incloem i per què. Se'ns fa evident que hi ha una millora quan es repensen aquests estudis i el(s) seu(s) currículum(s), quan s'inclouen noves investigacions acadèmiques que tenen cura de la diversitat identitària i cultural en el món actual, on tothom participem.

\section{Bibliografia}

Altmayer, C. (2013). Von der Landeskunde zur Kulturwissenschaft. Herausforderungen und Perspektiven F. T. Grub (dir.). Landeskunde Nord. Lang, 10-29.

Altmayer, C. (2007). Von der Landeskunde zur Kulturwissenschaft - Innovation oder Modetrend? Germanistische Mitteilungen. Zeitschrift des Belgischen Germanisten und Deutschlehrerverbands, 65, 7-21.

Altmayer, C. (2004). Cultural Studies - ein geeignetes Theoriekonzept für die kulturwissenschaftliche Forschung im Fach Deutsch als Fremdsprache? Zeitschrift für interkulturellen Fremdsprachenunterricht, 9/3, p. sense numerar.

Andrijević, M. (2010). Reflexiones en torno al uso de los materiales auténticos en la enseñanza de lenguas extranjeras, Colindancias - Revista de la red de hispanistas de Europa Central, $1,157-163$.

Hägi, S., Schweiger, H. (2015). Landeskunde und kulturelles Lernen Fremdsprache Deutsch, 52.

Lüsebrink, H. J., Vaillant, J. (dir.). (2013). Civilisation allemande/ Landes- Kulturwissenschaft Frankreichs: Bilan et perspectives dans l'enseignement et la recherche / Bilanz und Perspektiven in Lehre und Forschung. Presses Universitaires Septentrion.

UNESCO (1998). Higher Education in the Twenty-first Century. Vision and Action. World Conference on Higher Education. 
